\title{
Localization of nitric oxide synthase type III in the internal thoracic and radial arteries and the great saphenous vein: A comparative immunohistochemical study
}

\author{
Mario Gaudino, MD \\ Amelia Toesca, Bsc ${ }^{\text {b }}$ \\ Nicola Maggiano, Bsc ${ }^{b}$ \\ Claudio Pragliola, MD \\ Gianfederico Possati, MDa
}

Departments of Cardiac Surgery, Anatomy, Catholic University, Rome, Italy, and Pathology, Catholic University, Rome, Italy.

Received for publication May 21, 2002; revisions requested July 25, 2002; revisions received Aug 3, 2002; accepted for publication Sept 17, 2002.

Address for reprints: Mario Gaudino, MD, Divisione di Cardiochirurgia, Policlinico Universitario A. Gemelli, Largo A. Gemelli 8, 00168, Rome, Italy (E-mail: mgaudino@ tiscalinet.it).

J Thorac Cardiovasc Surg 2003;125:1510-5

Copyright (๑) 2003 by The American Association for Thoracic Surgery

$0022-5223 / 2003 \$ 30.00+0$

doi:10.1016/S0022-5223(03)00029-1
Background: Endothelial nitric oxide synthase type III is the key enzyme of the nitric oxide production in the vessel wall. In this study the localization of endothelial nitric oxide synthase type III within the wall of the human internal thoracic and radial arteries and the great saphenous vein was investigated.

Methods: Specimens were harvested from 23 patients undergoing surgical myocardial revascularization and submitted to light and electron microscope analysis using histochemical stainings and immunohistochemistry with specific antibodies antiendothelial nitric oxide synthase type III, Factor VIII, and $\alpha$-smooth muscle actin.

Results: Endothelial nitric oxide synthase type III was evident in the intima of all conduits and, unexpectedly, in the muscle cells of the media of muscular internal thoracic arteries and radial arteries. No endothelial nitric oxide synthase type III expression was found in the media of great saphenous veins. Semiquantitative analysis revealed a higher endothelial nitric oxide synthase type III expression in the wall of internal thoracic artery, particularly at the level of the media.

Conclusion: Endothelial nitric oxide synthase type III is expressed in the intima of the internal thoracic and radial artery and the great saphenous vein and in the muscle cells of the media of the internal thoracic and radial arteries. However, the internal thoracic artery shows a higher intensity of endothelial nitric oxide synthase type III expression, particularly within the media. The present study provides the first demonstration of the endothelial nitric oxide synthase type III expression at the level of the smooth muscle cells of the tunica media of systemic human arteries and can provide an histologic explanation for the better results of the internal thoracic artery when used for coronary artery bypass grafting.

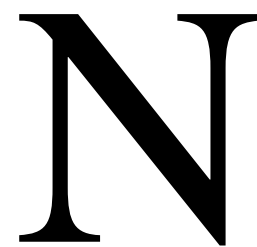

itric oxide (NO) is involved in several intracellular and intercellular signaling functions, such as regulation of blood vessel tone, hearth rhythm, cellular respiratory activity, response to inflammation, growth-promoting effects, neuronal signal transmission, vasodilatation, and resistance to atherosclerosis. ${ }^{1,2}$ Endogenous NO is produced by the enzyme nitric oxide synthase (NOS) from the conversion of L-arginine to L-citrulline. ${ }^{3}$ In mammals, three isoforms of NOS have been identified. NOS I (b-NOS, n-NOS) ${ }^{4}$ and NOS III (e-NOS $)^{5}$, regulated by $\mathrm{Ca}^{2+}$, are constitutively expressed respectively in neurons and in endothelial cells; in contrast NOS II (i-NOS) ${ }^{6}$ is an inducible form, $\mathrm{Ca}^{2+}$ independent, whose expression is induced by cytokines or other inflammatory agents. The three isoforms displayed regions of high homology but, at the same time, each one is characterized by structural differences that reflect its specific function. ${ }^{7}$ 
Although it is usually thought that NOS III is expressed only by the endothelial layer, ${ }^{8,9}$ the localization of this enzyme in the wall of the conduits used for surgical myocardial revascularization has not been investigated in detail. In the present study we used specific antibodies to localize NOS III within the human internal thoracic artery (ITA), radial artery (RA), and great saphenous vein (GSV).

\section{Methods}

After obtaining informed consent for specimen collection, samples of left ITA, RA, and GSV were collected from 23 patients during coronary artery bypass procedures. Main preoperative data of these patients are summarized in Table 1 . At the time of operation no patient was taking medications known to influence NOS III expression.

The ITA, RA, and were harvested pedicled using a technique described in details elsewhere, ${ }^{10,11}$ whereas the GSV was harvested using the conventional method.

The specimens for the microscope studies were obtained from the distal portion of the conduits immediately after harvesting and before surgical dilatation; the remaining part of the vessels was used for myocardial revascularization.

For light microscope study, tissue samples were immediately fixed in Bouin's solution at room temperature (RT) for 24 hours. They were then rinsed in phosphate-buffered saline (PBS; $\mathrm{pH} 7.4$ ), dehydrated in an ascending series of alcohol and embedded in paraffin via xylene. Serial transverse sections of $5 \mu \mathrm{m}$ were then cut and processed for histochemical (Mallory's trichrome method modified according to Azan, hematoxylin and eosin, Unna-TanzerLivini stain for elastic fibers) or immunohistochemical studies. For immunohistochemical experiments, endogenous peroxidase activity was quenched with $0.5 \% \mathrm{H}_{2} \mathrm{O}_{2}$ in absolute methanol for 30 minutes at RT; slides were then permeabilized with $0.2 \%$ Triton X-100 in PBS (20 min at RT) and incubated with 3\% normal goat serum in PBS (30 min at RT) to block nonspecific binding. Sections were then incubated overnight at $4{ }^{\circ} \mathrm{C}$ with the following primary antibodies: rabbit polyclonal anti-human NOS III (Santa Cruz Biotechnology, Santa Cruz, Calif, final concentration $2 \mu \mathrm{g} /$ $\mathrm{mL}$ ), rabbit polyclonal anti-human NOS III (Transduction Lab., $\mathrm{Ky}$, final concentration $5 \mu \mathrm{g} / \mathrm{mL}$ ), rabbit polyclonal anti-human Factor VIII (YLEM, Milan, Italy, diluted 1:150), mouse monoclonal anti-human $\alpha$-smooth muscle actin ( $\alpha$-SMA) (Novocastra Laboratories, Peterborough, UK, diluted 1:50). $\alpha$-SMA immunostaining was utilized to identify smooth muscle cells on the basis of the reported expression of this antigen by the smooth muscle cells. ${ }^{12}$ For double-staining experiments, antibodies to NOS III and to $\alpha$-SMA were incubated on the same section simultaneously.

Control sections were treated either with normal rabbit immunoglobulins or with NOS III antibody at the described concentration preabsorbed (ratio, 1:5) with the peptide against which the antibody was raised (Santa Cruz Biotechnology) at the same concentration used for primary antibodies.

Reactions were revealed by standard avidin-biotin peroxidase complex procedure (Vectastain Elite ABC Kit; Vector, Burlingame, Calif) using 3,3' diaminobenzidine tetrahydrochloride (DAB) (Sigma, Milan, Italy) and 3'-amino-9-ethylcarbazole (AEC Substrate Kit; Vector) as cromogens for anti-Factor VIII and
TABLE 1. Preoperative characteristics of the patients

\begin{tabular}{lccc}
\hline & ITA & RA & GSV \\
\hline Male/female & $8 / 4$ & $7 / 3^{*}$ & $6 / 4^{*}$ \\
Mean age (y) & $63.8 \pm 6.9$ & $69.1 \pm 6.7$ & $65.2 \pm 4.8$ \\
Hypertension & 7 & 6 & 5 \\
Diabetes & 3 & 2 & 2 \\
Smoking & 9 & 6 & 5 \\
Dislipemia & 6 & 4 & 5 \\
Familiar history of CAD & 6 & 5 & 5 \\
Previous AMI & 4 & 3 & 5 \\
CCS I & 2 & 1 & 0 \\
CCS II & 4 & 5 & 5 \\
CCS III & 6 & 4 & 5 \\
\hline
\end{tabular}

$A M I$, Acute myocardial infarction; $C A D$, coronary artery disease; CCS, Canadian Cardiovascular Society; GSV, great saphenous vein; ITA, internal thoracic artery; $R A$, radial artery.

* In 9 patients, both the radial artery and the saphenous vein were harvested.

anti- $\alpha$-SMA labeling, respectively. The anti-NOS III reaction was demonstrated by standard avidin-biotin alkaline phosphatase complex procedure (Vectastain Elite ABC-AP Kit; Vector) using BCIP-NBT (Sigma, Italy) as substrate.

Sections were examined under a Zeiss Axiophot (Aalen, Germany) light microscope.

For electron microscope observation, tissue samples were fixed in $4 \%$ paraformaldehyde in PBS for 4 hours at $4^{\circ} \mathrm{C}$, dehydrated in a graded ethanol series, and embedded in LR-White (London Resin Company, London, UK). Ultrathin sections were prepared using a Reichert ultramicrotome (Leica, Solms, Germany), collected on Formvar carbon-coated nickel grids, and then incubated overnight at $4{ }^{\circ} \mathrm{C}$ with the polyclonal antibody to human NOS III (Santa Cruz Biotechnology, final concentration $2 \mu \mathrm{g} / \mathrm{mL}$ ). After repeated washing in PBS, ultrathin sections were incubated with goat antirabbit IgG gold $(5 \mathrm{~nm})$ conjugated (Sigma, Chemicals) diluted 1:50 in PBS containing 1\% bovine serum albumin for 2 hours at RT. Negative controls were done by omitting the anti-human NOS III antibody, or adding the NOS III antibody at the described concentration preadsorbed with the peptide against which the antibody was raised (Santa Cruz Biotechnology) at the same concentration used for primary antibody. Sections were then postfixed in $2.5 \%$ glutaraldehyde for 10 minutes, lightly counterstained with lead citrate and observed with a Philips EM 400 microscope.

Microscopic analysis was performed by two experienced observers, blinded to each other, on a minimum of 30 sections for light microscopy and 15 for electron microscopy from different parts of each specimen. NOS III immunoreaction was then graded according to a 4-degree $(++++)$ semiquantitative scale; discordance was resolved after conjunct reevaluation.

\section{Results}

\section{Light Microscope Study}

All transverse sections from each specimen stained by histochemical techniques exhibited similar tissue architecture, and no pathological changes were noted.

Histochemical staining and anti $\alpha$-SMA immunoreaction revealed that 7 ITA specimens showed a muscular tunica 

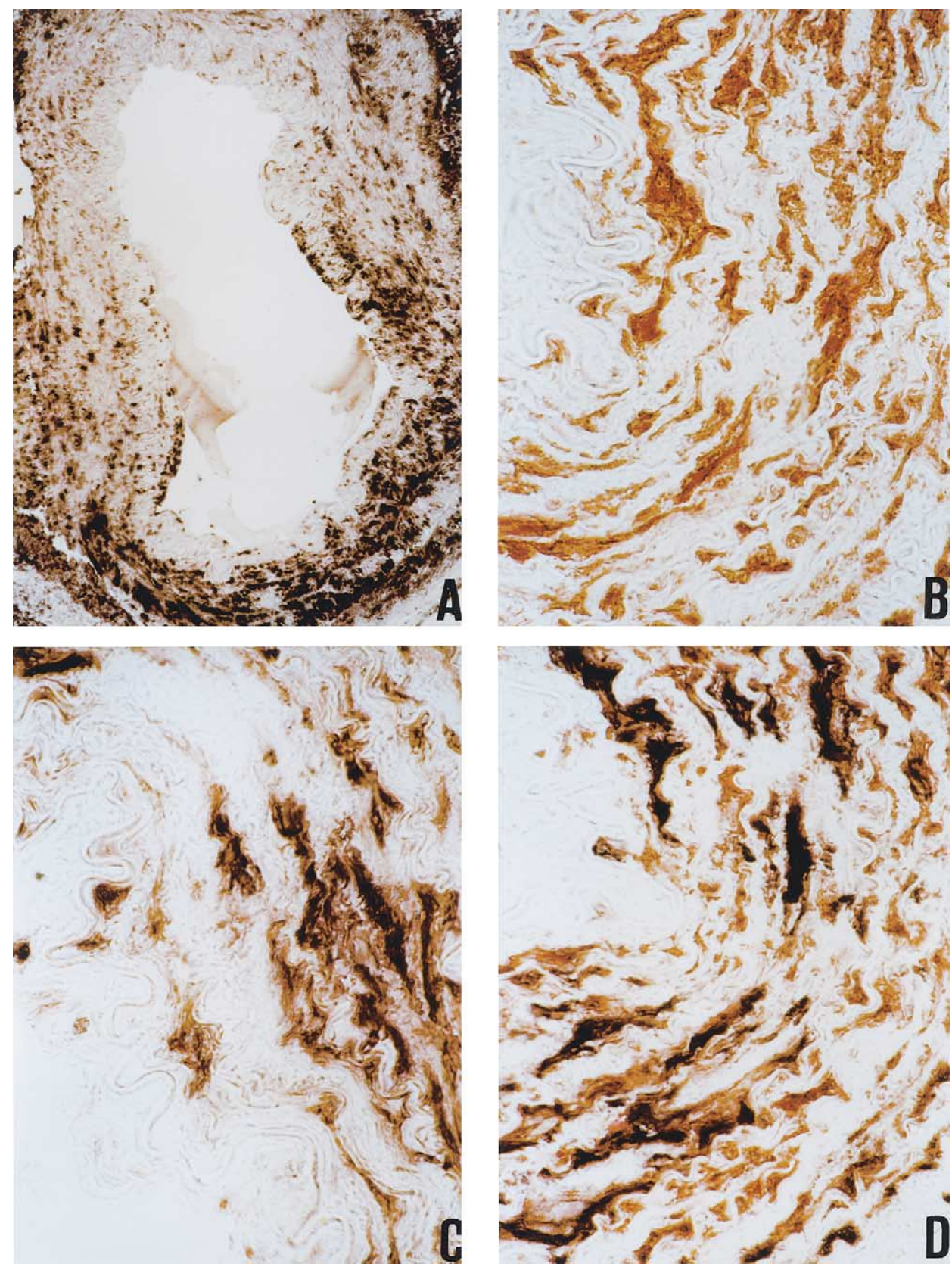

Figure 1. NOS III and $\alpha$-SMA immunohistochemistry on transverse sections from the muscular part of an internal thoracic artery specimen. A, NOS III immunoreactivity in endothelial cells and in smooth muscle cells of the tunica media $(80 \times)$. B, $\alpha$-SMA immunoreactivity in smooth muscle cells of the tunica media $(500 \times)$. C, NOS III immunoreactivity in smooth muscle cells of the tunica media and in some endothelial cells at higher magnification $(500 \times)$. D, Double immunostaining with anti $\alpha$-SMA (red) and anti NOS III (b/ue) antibodies, most of smooth muscle cells express both immunoreactions $(500 \times)$.

media, while the remaining 5 ITAs had an elastic wall. All examined RAs revealed a muscular tunica media, whereas GSV specimen contained only sparse smooth muscle cells in the media.

The immunohistochemical study using the antibody to Factor VIII showed a strong reaction in the cytoplasm of the endothelial cells, revealing the presence of an intact endothelial layer in all ITA, RA, and GSV specimens. In all cases, NOS III immunolocalization was observed in the cytoplasm of the endothelial cells of all types of conduits; not all of the endothelial cells expressed NOS III immunoreactivity and the reaction appeared weaker than that ob- 


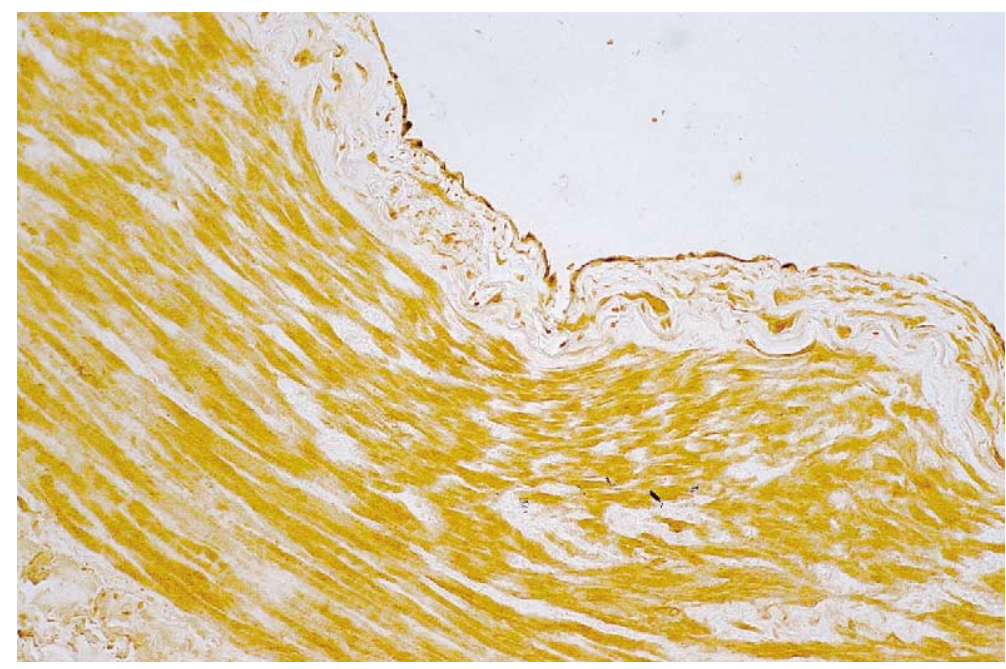

Figure 2. NOS III immunohistochemistry on transverse sections from a radial artery specimen. NOS III immunoreactivity in endothelial cells and in smooth muscle cells of the tunica media $(200 \times)$.

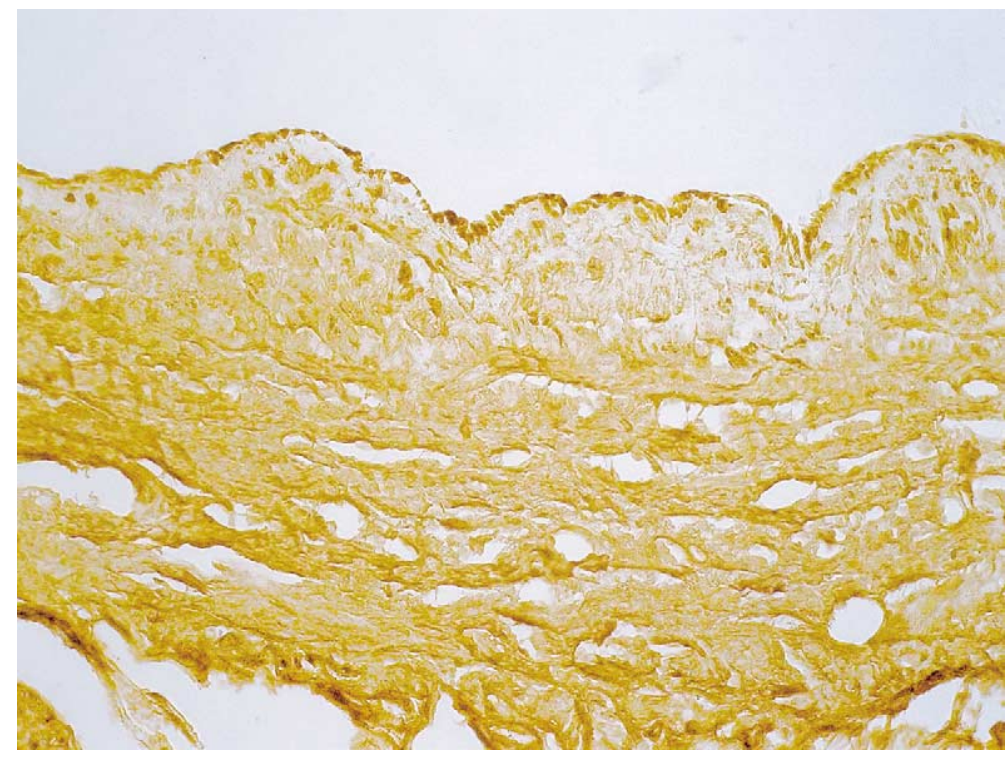

Figure 3. NOS III immunohistochemistry on transverse sections from a great saphenous vein specimen. NOS III immunoreactivity limited to endothelial cells $(200 \times)$.

served using the anti-Factor VIII antibody. Both anti-NOS III antibodies exhibited the same distribution pattern.

Unexpectedly, NOS III immunoreactivity was also observed within the smooth muscle cells of the tunica media from those ITAs with a muscular wall and from RA specimens (Figures 1 and 2). The intensity of NOS III immunoreactivity in the muscle cells varied widely from patient to patient, but the NOS III expression in muscle cells was present in all sections obtained from muscular ITAs and RAs. The localization in smooth muscle cells was confirmed by double immunostaining experiments where anti-
NOS III and anti- $\alpha$-SMA antibodies were simultaneously incubated on the same section; in these cases most of cells labeled by $\alpha$-SMA antibody also expressed NOS III immunoreactivity in the cytoplasm (Figure 1). No NOS III expression in the tunica media was found in sections from elastic-walled ITA and GSV specimens (Figure 3).

No immunoreactivity was detected in control sections incubated with either normal rabbit immunoglobulins or NOS III antibody preabsorbed with the peptide.

A semiquantitative evaluation of NOS III expression in the different conduits is provided in Table 2 . 


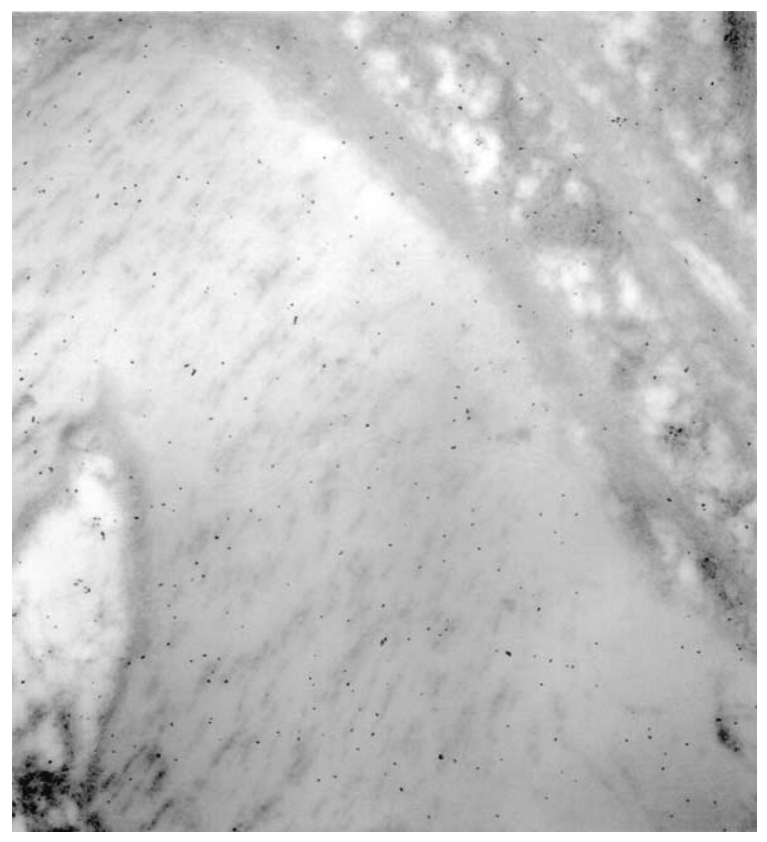

Figure 4. Electron microscope immunohistochemistry with antiNOS III antibody on transverse sections from the muscular part of an internal thoracic artery specimen. The immunoreactivity is localized in endothelial cells and in smooth muscle cells of the tunica media (original magnification: $25,000 \times$ ).

\section{Electron Microscope Study}

Transmission electron microscope study showed a NOS III distribution pattern similar to that observed by light microscope. NOS III localization was found in the endothelial cells of all conduits and in the smooth muscle cells of the arterial tunica media in all muscular ITAs and all RAs examined (Figure 4). No NOS III expression was observed in the tunica media of the ITAs with elastic media, in GSVs, and in the control sections.

\section{Discussion}

In the human cardiovascular system, NO is known to play a central role in several central functions, such as vasodilatation and resistance to atherosclerosis. ${ }^{1-3}$

Endogenous NO is produced by the three isoforms of the enzyme NOS from the conversion of L-arginine to L-citrulline. ${ }^{3-5}$

Although it is usually accepted that in the vessel wall NOS III is expressed only by the endothelial layer, ${ }^{8}$ the distribution of this isoform in human systemic arteries has not been directly investigated to date and no description of NOS III expression within the wall of conduits used for surgical myocardial revascularization has been published.

Our light and electronic microscope observations confirm the endothelial localization of NOS III in all types of conduits examined, although the ITA showed a higher de-
TABLE 2. Semiquantitative evaluation of NOS III expression in the different conduits

\begin{tabular}{lccc}
\hline & ITA & RA & GSV \\
\hline Intima & ++++ & +++ & +++ \\
Media & ++++ & $++/+++$ & - \\
\hline
\end{tabular}

GSV, Great saphenous vein; ITA, internal thoracic artery; $R A$, radial artery.

gree of endothelial expression of the enzyme. More surprisingly, our data provide the first description of an additional NOS III expression in the vascular smooth muscle cells of the media of both the ITA and (to a lesser extent) the RA, but not the GSV. The NOS III localization in smooth muscle cells was confirmed by double immunostaining experiments, where NOS III and $\alpha$-SMA antibodies were incubated on the same section. We found in fact that most of vascular muscle cells expressing $\alpha$-SMA immunoreactivity were also positive for NOS III (see Figure 1).

Medial expression of NOS III in systemic human arteries had not been described before, however, this finding is consistent with the localization of the enzyme in different types of muscle cells (cardiac myocites, myometrial smooth muscle cells, and erector pili muscle). ${ }^{13-15}$

Semiquantitative analysis revealed that, although NOS III was present in the intima of all conduits and in the media of muscular ITAs and all RAs, the intensity of the immunoreactivity was different in the three examined conduits and the ITA showed a higher NOS III expression in both the intima and, most of all, the media.

It is widely accepted that the ITA has peculiar biological features that render this artery an almost ideal conduit for surgical myocardial revascularization. Biological, morphological, and angiographic studies have, in fact, clearly demonstrated how this artery is somewhat protected from the development of atherosclerosis even in patients with severe coronary artery disease, and has better angiographic results than all other conduits used for coronary artery bypass grafting. ${ }^{16-18} \mathrm{NO}$ is known to play an important protective role against the development of atherosclerosis and, especially, graft disease. ${ }^{19,20}$ In fact, experimental investigations have clearly shown how the basal and stimulated release of NO are significantly greater in the ITA than in the RA and GSV, and it has been proposed that the higher NO production may be one possible explanation for the intrinsic protection from atherosclerotic disease and better patency rates of ITA grafts. ${ }^{21,22}$ Our results seem to suggest that higher NOS III expression (especially at the level of the media) may be one explanation for the peculiar biological properties of this conduit (although no information on the functional role of medial NOS III can be drawn from this immunohistochemical analysis).

In conclusion, NOS III is found in the intima of the ITA, RA, and GSV. Furthermore, the enzyme is also expressed in 
the muscle cells of the media of the ITA and the RA (but not the GSV), although the ITA shows a considerably higher intensity of medial localization. These findings provide one possible structural explanation for the peculiar biological properties of the human ITA and, coupled with the higher production of NO in the ITA compared to the RA and GSV as described, ${ }^{21,22}$ may explain the better patency rates of ITA grafts.

Further investigation should focus on the extent of muscular NOS III contribution to the total vascular NO production in different conditions and the factors that eventually modulate this action.

We thank Mr. Enrico Guadagni and Mr. Roberto Passalacqua, Institute of Anatomy, Catholic University, Rome, for technical and photographic assistance.

\section{References}

1. Palmer RMJ, Ferrige AG, Moncada S. Nitric-oxide release accounts for the biological activity of endothelium-derived relaxing factor. Nature. 1987;327:524-6.

2. Groves JT, Wang CC-Y. Nitric oxide synthase: models and mechanisms. Curr Opin Chem Biol. 2000;4:687-95.

3. Mayer B, Hemmens B. Biosynthesis and action of nitric oxide in mammalian cells. Trends Biochem Sci. 1997;22:477-81.

4. Knowles RG, Palacios M, Palmer RM, Moncada S. Formation of nitric oxide from L-arginine in the central nervous system: a transduction mechanism for stimulation of the soluble guanylate cyclase. Proc Natl Acad Sci U S A. 1989;86:5159-62.

5. Lamas S, Marsden PA, Li GK, Tempst P, Michel A. Endothelial nitric oxide synthase: molecular cloning and characterization of a distinct constitutive enzyme isoform. Proc Natl Acad Sci U S A. 1992;89:634852.

6. Marletta MA, Yoon PS, Iyengar R, Leaf CD, Wishnok JS. Macrophage oxidation of L-arginine to nitrite and nitrate: nitric oxide is an intermediate. Biochemistry. 1988;27:8706-11.

7. Stuehr DJ. Structure-function aspects in the nitric oxide synthases. Annu Rev Pharmacol Toxicol. 1997;37:339-59.

8. Pollock JS, Nakane M, Buttery LD, Martinez A, Springall D, Polak $\mathrm{JM}$, et al. Characterization and localization of endothelial nitric oxide synthase using specific monoclonal antibodies. Am J Physiol. 1993; 265:C1379-87.

9. Dikranian K, Trosheva M, Nikolov S, Bodin P. Nitric oxide synthase
(NOS) in the human umbilical cord vessels. An immunohistochemical study. Acta Histochem. 1994;96:145-53.

10. Gaudino M, Toesca A, Nori SL, Glieca F, Possati G. Effect of skeletonization of the internal thoracic artery on vessel wall integrity. Ann Thorac Surg. 1999;68:1623-7.

11. Manasse E, Sperti G, Suma H, Canosa C, Kol A, Martinelli L, et al. Use of the radial artery for myocardial revascularization. Ann Thorac Surg. 1996;62:1076-82.

12. Skalli O, Ropraz P, Trzeciak A, Benzonana G, Gillessen D, Gabbiani G. A monoclonal antibody against alpha smooth muscle actin: a new probe for smooth muscle differentiation. J Cell Biol. 1986;103:278796.

13. Weiner CP, Lizaasoain I, Baylis SA, Knowles RG, Charles IG, Moncada S. Induction of calcium-dependent nitric oxide synthesis by sex hormones. Proc Natl Acad Sci U S A. 1994;91:5212-6.

14. Gaangula PRR, Dong YL, Yallampalli C. Rat myometrial smooth muscle cells express endothelial nitric oxide synthase. Hum Reprod. 1997;12:561-8.

15. Shimizu Y, Sakai M, Umemura Y, Ueda H. Immunohistochemical localization of nitric oxide synthase in normal human skin: expression of endothelial-type and inducible-type nitric oxide synthase in keratinocytes. J Dermatol. 1997;24:80-7.

16. Loop FD, Lytle BW, Cosgrove DM, Stewart RW, Goormastic M, Williams GW, et al. Influence of the internal-mammary-artery graft on 10-year survival and other cardiac events. $N$ Engl J Med. 1986;314: 1-6.

17. Loop FD. Internal-thoracic-artery grafts. Biologically better coronary arteries. N Engl J Med. 1996;334:263-5.

18. Marx R, Jax TW, Plehn G, Schannwell CM, Horlitz M, Klein RM, et al. Morphological differences of the internal thoracic artery in patients with and without coronary artery disease-evaluation by duplexscanning. Eur J Cardiothorac Surg. 2001;20:755-9.

19. Tsui JCS, Souza DSR, Filbey D, Karlsson MG, Dashwood MR. Localization of nitric oxide synthase in saphenous vein grafts harvested with a novel "no-touch" technique: potential role of nitric oxide contribution to improved early graft patency rates. J Vasc Surg. 2002; 35:356-62.

20. Buttery LD, Chester AH, Springall DR, Borland JA, Michel T, Yacoub $\mathrm{MH}$, et al. Explanted vein grafts with an intact endothelium demonstrate reduced focal expression of endothelial nitric oxide synthase specific to atherosclerotic sites. J Pathol. 1996;179:197-203.

21. Liu ZG, Ge ZD, He GW. Difference in endothelium-derived hyperpolarizing factor-mediated hyperpolarization and nitric oxide release between human internal mammary artery and saphenous vein. Circulation. 2000;102(Suppl III):III-296-III301.

22. He GW, Liu ZG. Comparison of nitric oxide release and endotheliumderived hyperpolarizing factor-mediated hyperpolarization between human radial and internal mammary arteries. Circulation. 2001; 104(Suppl I):I-344-9. 